\title{
Testing the CAPM for the Brazilian Stock Market Using Multivariate GARCH between 1995 and 2012
}

\author{
Lucas Lucio Godeiro \\ Department of Agrotechnology and Social Science, \\ Federal Rural University of Semi-Arid, Brazil. \\ Email: lucasgodeiro@ufersa.edu.br
}

\begin{abstract}
The paper tests the CAPM for the Brazilian stock market using dynamic betas. The sample involves 28 stocks included in the Ibovespa portfolio as of March 21, 2012 and that were traded during the period from Jan. 01, 1995 to March 20, 2012. Dynamic betas were estimated and conditional betas contributed with larger explanatory power of excess cross section returns. The main contribution of the paper is the estimation of dynamic betas for Ibovespa shares, which can be useful for investors using Long $\mathrm{x}$ Short strategies.
\end{abstract}

Keywords: CAPM; Multivariate GARCH; Dynamic betas. JEL Classifications: G12; C32

\section{Introduction}

The Brazilian stock market has passed for changes in recent years. On scenario a macroeconomic stability after the Real Plan, the Ibovespa, principal index of Bovespa passed to approximately 4300 points in 1995 for about 60000 points in 2011. All this evolution occurred for several reasons, how investment foreign flow, increase of individual investors participation, inter alia. Despite this evolution, the stock market is a very volatile market. To get an idea, the 2008 crisis did Ibovespa fall of 70000 points to 29000 points in a few weeks. This requires an efficient risk management by managers and investors, so they are not surprised by sudden movements of the market.

One of the most widely used models in risk management by financial market is the Capital Asset Pricing Model (CAPM) developed by Sharpe (1964). The model use the betas how principal measure of non-diversifiable risk and emerged how alternative to efficient frontier Model Markowitz's (1952). The previous model to CAPM was required many algorithms, even for a small number of assets or portfolios. However, there is a discussion in the literature about the validity or otherwise of the CAPM. Several tests indicate validity, and various tests indicate that the model fault on several occasions. Another discussion in the literature is about the behavior of betas. Many studies admit that betas are constant over time and many reject this hypothesis.

Tambosi Filho et al. (2007) tested the static CAPM and the conditional CAPM in the Brazilian, American and Argentine market. Further according to the above authors, the CAPM conditional differs from the Conditional CAPM by incorporating the variation of the betas over time, allowing identifying variances and covariances that change in time.

Tambosi Filho et al. (2007) have used stock portfolios in their tests and selected the stocks that composed the portfolio via the criterion of liquidity and survivors stocks. As proxy of human capital the authors used the growth rate of labor income explained by GDP. The results obtained were as follows: the static CAPM without human capital explains the expected returns, the conditional CAPM without human capital also explains the expected returns in all markets more efficiently than static, as it showed a better fit, the conditional CAPM with human capital not explains the expected returns in any market, and the static CAPM with human capital also did not get a good power explanation.

Flister et al. (2011) tested whether the conditional CAPM is able to explain anomalies of size, moment and book-to-market. They concluded that the conditional CAPM, using a series of regressions of short term, showed gain negligible compared to alphas calculated with unconditional CAPM. They also found that the betas calculated by conditional CAPM vary with time, but not enough to the unconditional model alphas' were explained by the conditional model. 
Paiva (2005) tests the CAPM according to the methodology of Fama and MacBeth (1973) and finds evidence that the betas of companies that remaining in Ibovespa for a long period of time tend to be smaller than one, and with this characteristic the actions are defensive to investors.

Alencastro (2009) tests the static CAPM according to the methodology of Fama and Macbeth (1973) using stock portfolios. He systematizes research by dividing the period after the implementation of the Real Plan in three parts: 1994-1999, 1999-2004, 2004-2009. The author analyzes the microeconomic scenario of the stock market and also the macroeconomic situation of the period. The results were: validity of the CAPM in the first period, with low explanatory power, in the second period, the model is not validated, in the third period the model was validated after correction of heteroscedasticity and elimination of two outliers.

However, which is verified is a lack of empirical tests of the CAPM with dynamic betas in the Brazilian stock market, estimated with Multivariate GARCH DCC (Dynamic Conditional Correlation). Therefore, the research aims to test the CAPM for the Brazilian stock market using dynamic betas.

\section{Tests of the CAPM with Dynamic Approach}

The literature of tests of the CAPM with a dynamic approach born with the need of analysis of the non-diversifiable risk in the time domain, and also by the fact that the model coefficients aren't stable.

Harvey (1989) proposes a test of the capital asset pricing model that allows the conditional covariance vary in time. Also according to the author, conditional covariances time-varying have been modeled with the ARCH-M models (autoregressive conditional heteroskedasticity in the-mean model) of Engle et al. (1987). However, the disadvantage of the ARCH-M model, according to Harvey (1989a), is that it is not aggregated, ie, what works for a particular asset is not true for portfolios. So Harvey (1989a) chooses to use a new approach in which the conditional covariances are approximated by the product of the innovations of linear forecasts for the returns given the factors of the information set.

Harvey (1989) uses monthly returns of NYSE stocks between 1941 and 1987 and the returns of U.S. Treasury bonds as risk-free rate. As a proxy for the risk premium he uses the difference between the yields of BAA and AAA treasuries, according to Moody's. Harvey (1989) divided into ten portfolios the assets surveyed. The risk premiums, the return of dividends, among others, are used as instrumental variables. A dummy variable with a value of 1 for the month of January was used as a control variable.

In ordinary least squares regression by Harvey (1989), introduction of instrumental variables improves for $13.4 \%$ the model adjusting as compared to the result obtained by Campbell (1987) on the same sample. Then, the author tests the hypothesis that the conditional covariances are constants. The previous regression residuals are multiplied by the excesses of return of the assets and by the market excess return and regressed on the instrumental variables. If the null hypothesis is true, only the intercept of the regression, which is the risk free rate, should be significant and different from zero. For all portfolios, the null hypothesis is rejected, indicating that the covariances vary over time.

The next step of the study is to verify the relationship between the market return and volatility for each stock researched. The test is done using the following system:

$\varepsilon_{t}=\left[\begin{array}{ll}u_{m t} & e_{m t}\end{array}\right]=\left[\begin{array}{c}\left(r_{m t}-Z_{t-1} \delta_{m}\right)^{\prime} \\ \left\{r_{m t}-\lambda^{*}\left(Z_{t-1} \delta_{m}\right)^{2}\right\}^{\prime}\end{array}\right]$

The goal is to test whether the parameter $\lambda^{*}$ that measures the "cost of risk", is constant, and $Z_{t-1}$ represents the set of instrumental variables. This parameter indicates the expected return in excess of the market divided by the standard deviation of the market. The parameter can be estimated by the equation:

$\varepsilon_{t}=r_{m t}-\lambda^{*} \sigma_{m t}^{2}$

Where $\sigma_{m t}^{2}$ is the volatility of the market, estimated by the procedure of Davidian and Carroll (1987). All the tests carried out by the author also reject the null hypothesis, indicating that the parameter varies over time. 
The next step of this research was to estimate the coefficient which measures the relative risk aversion, as well as conditional covariance by the system:

$$
\varepsilon_{t}=\left[\begin{array}{lll}
u_{j t} & u_{m t} & e_{j t}
\end{array}\right]=\left[\begin{array}{c}
\left(r_{j t}-Z_{t-1} \delta_{j}\right)^{\prime} \\
\left(r_{m t}-Z_{t-1} \delta_{m}\right)^{\prime} \\
\left\{r_{m t}-\lambda\left(r_{j t}-Z_{t-1} \delta_{j}\right)\left(r_{m t}-Z_{t-1} \delta_{m}\right)\right\}^{\prime}
\end{array}\right]
$$

The results obtained by the researcher indicated that smaller firms had higher coefficient of relative risk aversion. Following was made a comparison between models with risk aversion parameter constant and varying in time. The author concludes that the model with constant parameter has better explanatory power of the data.

$\mathrm{Ng}$ (1991) tests the CAPM with multivariate GARCH approach to verify if the proxy of the market portfolio lies on the border of mean-variance conditional, if the relationship in cross-section between risk premium of an asset and their covariances are linear or proportional, and if the relationship between risk premium market and its conditional variance is constant over time.

The study of the author cited above uses a multivariate GARCH process which allows conditional returns excess, conditional variances and conditional covariances change over time. The study finds evidence that the price of risk varies with the market volatility and the market risk premium is linearly related to the conditional variance of the market with negative intercept, which is inconsistent with the proposition of Merton (1980) of CRRA type preferences. However, the negative intercept is consistent with Bollerslev et al. (1988) and Harvey (1989). The work of Ng (1991), however, uses monthly data and a model with constant conditional correlation, which is not a good assumption when working with financial data.

Wang (2003) presents a new test of the conditional CAPM, an extension of the work of Jagannathan and Wang (1996) and the three-factor model of Fama and French (1993). Also according to Wang (2003), a dynamic version of the CAPM has generally better performance than static models.

According to this author, dynamic models are attractive and challenging to be tested, mainly because they do not have a guide showing how the betas vary with variables that represent conditioning information. The authors use a nonparametric representation of the stochastic discount factor implicit in a conditional linear model of pricing with factors. This methodology allows to perform tests that are free functional specifications bad of the dynamic of conditional betas, of the risk premium and the discount stochastic factor. As results, the authors found that the shape of nonparametric CAPM performs better than the unconditional CAPM and the conditional CAPM is rejected statistically. Other implications of this research are that pricing errors has a strong pattern in volatility, but not on average.

Also according to Wang (2003), a critical issue in the discussion of empirical tests of the CAPM is how to measure expected returns that vary over time. Different ways of modeling the systematic risk with conditional and non-conditional models can produce various opinions if the moment's strategy and gains are consistent with the time-varying expected returns. Also according to the author above, nonparametric tests can avoid the effects of misspecification of the model, but usually the underlying nonparametric estimators converge more slowly than parametric estimators for equilibrium.

The sample used by Wang (2003) consists of stocks traded on the NYSE between January 1947 and December 1995. The author divides the sample into four panels according to company size and the conditioning variables. Then, the betas are estimated by means of a multivariate function to verify whether the betas are nonlinear. A visual inspection of the graph of betas against time suggests that betas are not linear. The next step was to test the nonlinearity of betas through the LM test of Andrews (1993) and following the model of explicit beta of Ghysels (1998). In fact, the author notes that betas are not linear in relationship to returns, which gives evidence that the conditional model is not valid.

The work of Kumar et.al (2008) investigates the role of information on the cross-section of asset returns when investors are faced with uncertain information. For both, the authors use variables such as oil prices, market volatility and exchange rates as variables to be tested.

Kumar et. al (2008) reject the hypothesis of CAPM that information is perfect and the prices converge to the equilibrium even with the new information because, in their opinion, many market professionals explain market movements in terms of "resolution of uncertainty ". Yet according to the 
authors, the assumption that investors have complete information about the generating process of asset returns is clearly extreme. In reality, investors are uncertain as to parameters that governing these processes, besides facing the risk inherent in the production and investment. Another research problem concerns the quality of investor information and how to incorporate them into their forecasting models.

To facilitate comparability with the standard CAPM, Kumar et. al (2008) constructed a model in which returns are multivariate normal, but investors are uncertain as to the first and second moment of the joint distribution of returns and information. A crucial implication of learning from information of uncertain quality is that both the first and the second moment of the conditional expected returns are dependent on information, and therefore stochastic. In equilibrium, assets are priced according to their intrinsic systematic risk. Furthermore, the market risk premium and volatility are dependent on information. The hypothesis put forward by the authors is that the portion of the change in aggregate risk of the market depends on macroeconomic factors such as the price of oil, for example. A fluctuation in oil prices causes changes in cash flows of the companies and thus influences the prices of their assets in the stock exchange.

To investigate the relationship between innovations in volatility and cross section of returns, Kumar et. al. (2008) used the following specification:

$$
R_{a t}-R_{f t}=\alpha_{a}+\pi_{a} \delta\left(\sigma_{m t}^{2}\right)+\gamma_{a} a g e+\lambda\left[\delta\left(\sigma_{m t}^{2}\right) * a g e\right]+\beta_{a}\left(R_{m t}-R_{f t}\right)
$$

The coefficient $\pi_{a}$ had a negative sign, indicating an inverse relationship between innovations in volatility and excess return. In the following section, is tested if innovations in oil prices affect the returns via the equation:

$$
R_{a t}-R_{f t}=\alpha_{a}+\pi_{a} O I L+\beta\left(R_{m t}-R_{f t}\right)
$$

The results of Kumar et. al. (2008) show that increases in oil prices negatively affects the cash flows of the companies that consume oil and not positively affects the cash flows of firms producing. The results of author may suffer some sort of questioning, given that high oil prices could positively affect the cash flows of oil companies. If the oil companies have a large weight in the composition of the stock index, which is the case of Petrobras in Brazil, the aggregate result may be an improvement in market expectations.

Then, the authors simulate the effects of an innovation in the exchange rate may cause in the stock return of firms exporters and importers. For importer firms there is an inverse relation and to the exporter firms the parameters were also negative, but not significant.

The next step of the research of Kumar et. al. (2008) was to test whether the dispersion of opinions of market analysts explain the cross section of excess returns. The authors found an inverse relationship between the increase in the dispersion of analysts' opinions and excess returns. Finally, we analyze the effect of the announcement of share repurchases and dividend payments on the estimated betas of firms. There is a fall in the average estimated betas when announced dividends and share repurchases, indicating fall in non-diversifiable risk.

Mamaysky, Spiegel and Zhang (2008) use the Kalman Filter to estimate the trajectory of the betas of investment funds. The method is justified by the inability of the static model of capture the dynamics of the market, an important component of analysis by managers. The results indicate that funds follow strategies quite dynamic. The betas estimated by Kalman filter are smoother and less prone to sudden changes when compared to betas estimated by ordinary least squares.

Hueng and Huang (2008) investigated the asymmetrical relationship between risk and return using the CAPM with time-varying betas. The authors specify with the following equation the time-varying betas:

$$
\begin{aligned}
& R_{a t}-R_{f t}=\alpha_{a t}+\beta_{a t}\left(R_{m t}-R_{f t}\right)+v_{t} \\
& \beta_{a t}=\beta_{a t-1}+\eta_{t}^{\beta} \\
& \alpha_{a t}=\alpha_{a t-1}+\eta_{t}^{\alpha}
\end{aligned}
$$

The research of Hueng and Huang (2008) examined the daily closing prices of 358 assets comprising the S \& P 500 from 1987 to 2003. The authors compose their portfolios according to market sectors which companies belong. As a result, the authors find that there is indeed an 
asymmetrical relationship between risk and return, as there is a considerable difference between static betas and average dynamic betas.

This research estimates the dynamic betas by two methods: DCC-Multivariate GARCH and Kalman Filter. The estimation by two different methods aims to identify which types of betas have greater explanatory power of the cross section of returns.

\section{Data}

Were researched the daily closing prices of the shares of Ibovespa traded throughout the period of Jan. 01, 1995 to March 20, 2012. The period of Ibovespa composition taken as a reference was the last day of the sample. All prices were adjusted for dividends, splits and any other earnings. Also were researched the daily closing Ibovespa as a proxy for the market return and the Selic rate as a proxy of the risk-free return. A total of 28 shares were surveyed with 4493 observations each. The total sample, including Ibovespa and Selic, has the total of 134,790 observations. Then were calculated the compound return of the shares and the index, for thus, be obtained the excess returns of the market and of each stock. Table 1 shows the surveyed companies and their ticker on the BOVESPA.

Table 1. Companies and ticker

\begin{tabular}{|c|c|c|}
\hline Company & Type & Ticker \\
\hline Ambev & $\mathrm{PN}$ & ambv4 \\
\hline Bradesco & $\mathrm{PN}$ & bbdc4 \\
\hline Braskem & $\mathrm{PN}$ & brkm5 \\
\hline Brasil Telecom & $\mathrm{PN}$ & brto4 \\
\hline Banco do Brasil & $\mathrm{ON}$ & bbas3 \\
\hline Cemig & $\mathrm{PN}$ & cmig4 \\
\hline Souza Cruz & ON & cruz3 \\
\hline Siderúrgica Nacional & $\mathrm{ON}$ & csna3 \\
\hline Eletrobras & $\mathrm{ON}$ & elet3 \\
\hline Eletrobras & $\mathrm{PN}$ & elet6 \\
\hline Embraer & $\mathrm{ON}$ & embr3 \\
\hline Fibria & $\mathrm{ON}$ & fibr3 \\
\hline Gerdau & $\mathrm{PN}$ & ggbr4 \\
\hline Gerdau Metalúrgica & $\mathrm{PN}$ & goau4 \\
\hline Itaú Investimentos & $\mathrm{PN}$ & itsa4 \\
\hline Itaú Unibanco & $\mathrm{PN}$ & itub4 \\
\hline Klabin & $\mathrm{PN}$ & klbn4 \\
\hline Lojas Americanas & $\mathrm{PN}$ & lame4 \\
\hline Light & $\mathrm{ON}$ & ligt3 \\
\hline Lojas Renner & $\mathrm{ON}$ & lren3 \\
\hline Pão de Açúcar & $\mathrm{PN}$ & pcar4 \\
\hline Petrobrás & $\mathrm{ON}$ & petr3 \\
\hline Petrobrás & $\mathrm{PN}$ & petr4 \\
\hline Usiminas & $\mathrm{ON}$ & usim3 \\
\hline Usiminas & $\mathrm{PN}$ & usim5 \\
\hline Vale & $\mathrm{ON}$ & vale3 \\
\hline Vale & $\mathrm{PN}$ & vale5 \\
\hline Vivo & PN & vivt4 \\
\hline
\end{tabular}




\section{Econometric Model}

This session shows the Econometric Models used by research. The Models are the Multivariate Generalized Autoregressive Conditional Heteroskedasticity (MGARCH) and Kalman Filter.

The betas estimated with MGARCH are called conditional betas. The model is known DCC (Dynamic Conditional Correlation)-MGARCH because the correlations are time-varying. For each asset is estimated a univariate model, but also for the Ibovespa and then are estimated the multivariate part of the model and the unconditional correlation. With the outputs of MGARCH are calculated conditional variances of asset and market, the conditional covariance between the asset and the market and unconditional correlation between the two. To calculate the beta conditional splits the conditional covariance between the asset and the market by the conditional variance of market. The Kalman filter estimates from the variance-covariance matrix and state space representation of what is called structural betas. To obtain the structural betas will be estimated level local model with the level of the variance fixed. It is expected that the structural betas have a behavior softer than the conditional betas, given the characteristics of the cited methods which will be detailed below.

\subsection{Estimation of the CAPM with Multivariate GARCH}

The research uses the model MGARCH following the approach of Tse and Tsui (2002). This method allows the estimation of dynamic betas from the conditional covariance and conditional variance obtained. The choice of model is justified because the authors incorporate correlations varying in time, while satisfying the condition that the conditional variance matrix is positive definite. The MGARCH model of Tse and Tsui (2002) is an innovation model of Bollerslev (1988) and the model of Engle and Kroner (1995).

Considering $r_{t}, t=1, \ldots, T$ the set of multivariate observations of excess returns of stocks and the market, each with $K$ elements, where $r_{t}=\left(r_{1 t}, \ldots, r_{K t}\right)$. The conditional variance, assuming that $r_{t}$ time-varying, is defined by:

$\operatorname{Var}\left(r_{t} \mid \Phi_{t-1}\right)=\Omega_{t}$

Where $\Phi_{t}$ represents the set of information at time t. The variance of the elements of $\Omega_{t}$ is represented by $\sigma_{i t}$, for $i=1, \ldots, K$ and the covariances are represented by $\sigma_{i j t}$, where $1 \leq i<j \leq K$. Defining $D_{t}$ the diagonal matrix $K \times K$ in which the ith diagonal element is $\sigma_{i j t}$, you can define $\varepsilon_{t}=D_{t}^{-1} r_{t} . \quad \varepsilon_{t}$ represents the standardized residual and it is assumed that it is IID with zero mean and variance matrix $\Gamma_{t}=\left\{\rho_{i j t}\right\}$. Therefore, the correlation matrix for $r_{t}$ is denoted by $\Omega_{t}=D_{t} \Gamma_{t} D_{t}$. The conditional variance follows formulation vech-diagonal developed by Bollerslev (1988). Then, each term in the conditional variance follows a univariate $\operatorname{GARCH}(p, q)$ given by equation:

$$
\sigma_{i t}^{2}=\omega_{i}+\sum_{h=1}^{p} b_{i h} \sigma_{i, t-h}^{2}+\sum_{h=1}^{q} a_{i h} r_{i, t-h}^{2}, \quad i=1, \ldots, K
$$

Where $\omega_{i}, a_{i h}, b_{i h}$ are nonnegative and $\sum_{h=1}^{p} a_{i h}+\sum_{h=1}^{q} b_{i h}<1$ for all $i=1, \ldots, K$. The conditional correlation matrix varying in time is defined by the equation:

$\Gamma_{t}=\left(1-\theta_{1}-\theta_{2}\right) \Gamma+\theta_{1} \Gamma_{t-1}+\theta_{2} \Psi_{t-1}$

Where $\Gamma=\left\{\rho_{i j t}\right\}$ is a positive definite matrix parameters, of size $K \times K$, time variant with unitary diagonal elements and $\Psi_{t-1}$ is a matrix which the elements are functions of the lagged observations of $r_{t}$. The parameters $\theta_{1}$ and $\theta_{2}$ are nonnegative and it is assumed that the restriction of which $\theta_{1}+\theta_{2} \leq 1$.

It is observed that $\Psi_{t-1}$ is analogous to $r_{i, t-1}^{2}$ of $\operatorname{GARCH}(1,1)$. However, with $\Gamma_{t}$ is, according to Tse and Tsui (2002), a standardized measure, $\Psi_{t-1}$ need depend on standardized residuals lagged $\varepsilon_{t}$. Defining $\Psi_{t}=\left\{\psi_{i j t}\right\}, \Psi_{t-1}$ follows the specification: 
$\psi_{i j, t-1}=\frac{\sum_{h=1}^{M} \varepsilon_{i, t-h} \varepsilon_{j, t-h}}{\sqrt{\left(\sum_{h=1}^{M} \varepsilon_{i, t-h} \sum_{h=1}^{M} \varepsilon_{j, t-h}\right)}}, \quad 1 \leq i<j \leq K$

$\psi_{t-1}$ is the correlation matrix of $\left\{\varepsilon_{t-1}, \ldots, \varepsilon_{t-M}\right\}$. Defining $\mathrm{E}_{t-1}$ a matrix $K \times M$ given by $\mathrm{E}_{t-1}=\left\{\varepsilon_{t-1}, \ldots, \varepsilon_{t-M}\right\}$. If $B_{t-1}$, is a diagonal matrix $K \times K$ in where the ith diagonal element is $\left(\sum_{h=1}^{M} \varepsilon_{i, t-h}^{2}\right)^{1 / 2}$ for $i=1, \ldots, K$, we have:

$\Psi_{t-1}=B_{t-1}^{-1} \mathrm{E}_{t-1} \mathrm{E}_{t-1}^{\prime} B_{t-1}^{-1}$

The conditional $\log$-likelihood $\ell_{t}$ of the observation $r_{t}$ is given by:

$$
\begin{aligned}
& \ell_{t}=-\frac{1}{2} \ln \left|D_{t} \Gamma_{t} D_{t}\right|-\frac{1}{2} r_{t}^{\prime} D_{t}^{-1} \Gamma_{t}^{-1} D_{t}^{-1} r_{t} \\
& \ell_{t}=-\frac{1}{2} \ln \left|\Gamma_{t}\right|-\frac{1}{2} \sum_{i=1}^{K} \ln \sigma_{i t}^{2}-\frac{1}{2} r_{t}^{\prime} D_{t}^{-1} \Gamma_{t}^{-1} D_{t}^{-1} r_{t}
\end{aligned}
$$

Define $\theta=\left(\omega_{1}, a_{11}, \ldots, a_{1 q}, b_{11}, \ldots, b_{1 p}, \omega_{2}, \ldots, a_{K q}, \rho_{12}, \ldots, \rho_{K-1, K}, \theta_{1}, \theta_{2}\right)$ as the vector of parameters and maximizing $\ell$ in relation to $\theta$, we have $\hat{\theta}$, where $\ell=\sum \ell_{t}$.

\subsection{Estimation of the CAPM with Kalman Filter}

The CAPM with beta time-varying by making the hypothesis that the risk-free rate is zero is defined by:

$r_{t}=\beta_{t} r^{\prime}{ }_{m t}+\varepsilon_{t}$

The beta time-varying, according to Hamilton (1994), is given by the equation:

$\left(\beta_{t+1}+\bar{\beta}\right)=F\left(\beta_{t}-\bar{\beta}\right)+v_{t+1}$

If the eigenvalues of the matrix $F(k \times k)$ are inside the unit circle, so $\bar{\beta}$ is the vector of mean values of coefficients. Thus, the state vector will be $\xi_{t}=\beta_{t}-\bar{\beta}$ and (13) can be rewritten as follows: $r_{t}=\bar{\beta} r_{m t}^{\prime}+\xi_{t} r^{\prime}{ }_{m t}+\varepsilon_{t}$

Define $\wp_{t-1}$ as a set of conditional information to $r_{m t}$ in t-1 and $P_{t \mid t-1}$ as the variance-covariance matrix of the process, the maximum likelihood function is represented by the equation:

$$
\begin{aligned}
& \sum_{t=1}^{T} \log f\left(r_{t} \mid r_{m t}, \wp_{t-1}\right)=-\left(\frac{T}{2}\right) \log (2 \pi)-\left(\frac{1}{2}\right) \sum_{t=1}^{T} \log \left(r_{m t}^{\prime}{ }_{t \mid t-1} P_{m t}+\sigma^{2}\right) \\
& -\left(\frac{1}{2}\right) \sum_{t=1}^{T} \frac{\left(r_{t}-\bar{\beta} r_{m t}^{\prime}-\xi_{t \mid t-1} r_{m t}^{\prime}\right)^{2}}{\left(r_{m t}^{\prime} P_{t t t-1} r_{m t}+\sigma^{2}\right)}
\end{aligned}
$$

\section{Results}

Table I.1 in appendix I presents descriptive statistics for the excess returns of assets surveyed, for the excess market return and the Selic rate. It is observed that thirteen of assets and the Ibovespa don't have excess return positive. The analysis table identifies some "stylized facts" of financial time series described by Daníelsson (2011). The serial autocorrelation found in series through the test Q indicates that there are clusters of volatility, in other words, periods of high volatility which are preceded by periods of low volatility. The values of the autocorrelations of squared excess returns show that there is nonlinear dependence of the series, because the square of the excess return has a larger structure than the excess return. Finally, the value of kurtosis greater than three found in all the asset is signal that distributions have fat tails and, therefore don't follow a normal distribution. 
The first procedure to test the CAPM with dynamic betas is the estimation of own betas. The estimation is performed with DCC-MGARCH model, developed by Tse and Tsui (2002). In the mean equation were estimated vector autoregressive to remove the serial correlation and used the residuals of this estimation. The model provides the conditional covariances and conditional variances. To retrieve the conditional betas were divided the conditional covariance between the excess returns of the assets and excess return of the market by the conditional variance of excess return of the market. In the financial market, it is known that the market rises with low volatility and falls with high volatility. When the series exhibit this asymmetry is used TGARCH model developed by Glosten et al. (1993). This model uses a dummy variable equal to 1 if the return of innovation in variance equation is negative. Thus, greater weight is given to negative returns. For each asset models were estimated with and without asymmetry and chosen the best model according to the Schwarz information criterion. Table 2 shows the results.

Table 2. DCC-MGARCH Model

\begin{tabular}{|c|c|c|c|c|c|c|c|c|c|c|}
\hline Asset & $\omega \times 10^{4}$ & $a_{1}$ & $a_{2}$ & $b_{1}$ & $b_{2}$ & $\gamma_{1}$ & $\gamma_{2}$ & $\theta_{1}$ & $\theta_{2}$ & $\rho_{i, i b o v}$ \\
\hline ambv4 & $0.08^{*}$ & 0.21 & -0.15 & 0.92 & & & & 0.94 & 0.02 & 0.51 \\
\hline ibov & 0.13 & 0.10 & 0.02 & 0.84 & & & & & & \\
\hline bbdc4 & 0.13 & 0.08 & -0.04 & 0.89 & & 0.14 & $-0.04 *$ & 0.96 & 0.02 & 0.86 \\
\hline ibov & 0.15 & -0.03 & 0.07 & 0.85 & & 0.22 & -0.07 & & & \\
\hline brkm5 & $0.10^{*}$ & 0.15 & -0.10 & 0.92 & & $-0.02 *$ & $0.07 *$ & 0.97 & $0.01 *$ & 0.67 \\
\hline ibov & 0.14 & -0.03 & 0.05 & 0.86 & & 0.23 & -0.07 & & & \\
\hline brto4 & $0.04^{*}$ & 0.08 & -0.07 & 1.33 & $-0.36^{*}$ & $0.09 *$ & $-0.07^{*}$ & 0.96 & 0.02 & 0.75 \\
\hline ibov & 0.01 & -0.03 & 0.04 & 1.63 & -0.65 & 0.28 & -0.26 & & & \\
\hline bbas3 & 0.02 & 0.16 & -0.15 & 1.41 & -0.43 & & & 0.97 & 0.01 & 0.76 \\
\hline ibov & 0.17 & 0.09 & 0.07 & 0.42 & 0.36 & & & & & \\
\hline cmig4 & 0.11 & 0.04 & & 0.90 & & 0.06 & & 0.98 & 0.01 & 0.82 \\
\hline ibov & 0.14 & $0.02 *$ & & 0.86 & & 0.14 & & & & \\
\hline cruz3 & $0.06^{*}$ & 0.19 & -0.13 & 0.93 & & & & 0.97 & $0.01 * *$ & 0.51 \\
\hline ibov & 0.12 & 0.10 & 0.01 & 0.85 & & & & & & \\
\hline csna3 & 0.10 & 0.07 & -0.05 & 1.12 & -0.18 & 0.14 & -0.09 & 0.97 & 0.01 & 0.86 \\
\hline ibov & 0.12 & -0.03 & 0.06 & 1.02 & -0.14 & 0.22 & -0.09 & & & \\
\hline elet3 & $0.08^{*}$ & 0.18 & -0.10 & 0.91 & & & & 0.98 & 0.01 & 0.89 \\
\hline ibov & 0.12 & 0.09 & 0.02 & 0.85 & & & & & & \\
\hline elet6 & $0.04 *$ & 0.07 & -0.05 & 1.30 & -0.33 & 0.14 & -0.12 & 0.98 & 0.01 & 0.89 \\
\hline ibov & 0.01 & -0.03 & 0.04 & 1.62 & -0.65 & 0.27 & -0.26 & & & \\
\hline embr3 & 0.06 & 0.14 & & 0.87 & & & & 0.98 & 0.01 & 0.43 \\
\hline ibov & 0.12 & 0.11 & & 0.85 & & & & & & \\
\hline fibr3 & 0.07 & 0.15 & -0.14 & 1.44 & -0.46 & & & 0.98 & 0.01 & 0.68 \\
\hline ibov & 0.18 & 0.10 & 0.07 & 0.30 & 0.47 & & & & & \\
\hline ggbr4 & 0.58 & 0.06 & & 0.81 & & 0.09 & & 0.97 & 0.02 & 0.89 \\
\hline ibov & 0.14 & 0.02 & & 0.87 & & 0.14 & & & & \\
\hline goau4 & 0.18 & 0.10 & -0.07 & 0.90 & & 0.12 & -0.03 & 0.97 & 0.02 & 0.26 \\
\hline ibov & 0.12 & -0.03 & 0.05 & 0.87 & & 0.24 & -0.11 & & & \\
\hline itsa4 & 0.09 & 0.02 & & 0.91 & & 0.08 & & 0.97 & 0.02 & 0.84 \\
\hline ibov & 0.14 & 0.02 & & 0.87 & & 0.14 & & & & \\
\hline itub4 & $0.10^{*}$ & 0.06 & -0.04 & 0.92 & & 0.12 & $-0.03 *$ & 0.96 & 0.02 & 0.85 \\
\hline
\end{tabular}




\begin{tabular}{|c|c|c|c|c|c|c|c|c|c|c|}
\hline ibov & 0.12 & -0.03 & 0.05 & 0.87 & & 0.25 & -0.13 & & & \\
\hline klbn4 & 0.42 & 0.09 & & 0.82 & & 0.08 & & 0.98 & $0.01 *$ & 0.66 \\
\hline ibov & 0.14 & 0.02 & & 0.86 & & 0.15 & & & & \\
\hline lame4 & 0.02 & 0.15 & -0.14 & 1.47 & -1.49 & 0.05 & -0.03 & 0.98 & 0.01 & 0.65 \\
\hline ibov & 0.03 & -0.03 & 0.04 & 1.46 & -0.50 & 0.26 & -0.22 & & & \\
\hline ligt3 & $0.04 *$ & 0.19 & -0.14 & 0.94 & & & & 0.96 & 0.02 & 0.64 \\
\hline ibov & 0.12 & 0.10 & 0.01 & 0.85 & & & & & & \\
\hline 1ren3 & $0.03 *$ & $0.08 *$ & -0.07 & 1.47 & -0.49 & 0.19 & -0.17 & 0.76 & $0.03^{*}$ & 0.55 \\
\hline ibov & 0.00 & 0.07 & -0.06 & 1.72 & -0.74 & 0.28 & -0.26 & & & \\
\hline pcar4 & $0.01 *$ & $0.05 *$ & & 0.93 & & 0.04 & & 0.97 & 0.01 & 0.51 \\
\hline ibov & 0.08 & 0.01 & & 0.89 & & 0.15 & & & & \\
\hline petr3 & $0.13^{*}$ & 0.04 & & 0.90 & & 0.08 & & 0.97 & 0.01 & 0.81 \\
\hline ibov & 0.08 & 0.01 & & 0.88 & & 0.15 & & & & \\
\hline petr4 & 0.20 & 0.03 & & 0.86 & & 0.12 & & 0.97 & 0.01 & 0.88 \\
\hline ibov & 0.08 & 0.01 & & 0.88 & & 0.15 & & & & \\
\hline usim 3 & $0.10^{*}$ & 0.63 & -0.47 & 1.14 & -0.25 & & & 0.97 & 0.02 & 0.59 \\
\hline ibov & 0.18 & 0.10 & 0.08 & $0.35^{* *}$ & $0.41 *$ & & & & & \\
\hline usim5 & $0.18 *$ & $0.08 *$ & $-0.05 *$ & 0.90 & & $0.09 *$ & $-0.03 *$ & 0.97 & 0.02 & 0.84 \\
\hline ibov & 0.13 & -0.03 & 0.06 & 0.86 & & 0.22 & -0.09 & & & \\
\hline vale3 & 0.14 & 0.05 & & 0.89 & & 0.06 & & 0.98 & 0.01 & 0.39 \\
\hline ibov & 0.14 & $0.02 *$ & & 0.86 & & 0.14 & & & & \\
\hline vale5 & 0.00 & 0.16 & -0.15 & 1.69 & -0.71 & & & 0.97 & 0.01 & 0.93 \\
\hline ibov & 0.00 & 0.13 & -0.12 & 1.76 & -0.77 & & & & & \\
\hline vivt4 & $0.17^{*}$ & 0.06 & & 0.86 & & 0.08 & & 0.97 & 0.01 & 0.80 \\
\hline ibov & 0.14 & $0.01 *$ & & 0.87 & & 0.14 & & & & \\
\hline
\end{tabular}

Source:Authors.

$*, * *$ and $* * *$ indicate no significance at levels of $1 \%, 5 \%$ and $10 \%$, respectively.

The estimated parameters were significant at the 5\% level and all the conditional correlations were significant at $1 \%$. In only nine of twenty-eight assets researched the best estimated model showed no asymmetry. The multivariate estimation obtained better performance with errors following the t-student distribution for all pairs of assets. The asset of greatest unconditional correlation with the Ibovespa was the preferred share of Vale, which is justified by the same have a great weight in the composition of the index. The stock that had the lowest unconditional correlation was preferred share of Gerdau Metalúrgica. Shares of banks surveyed have unconditional correlation high with the Ibovespa.

The parameters of asymmetry estimated are consistent with the theory, indicating that there is volatility increase if the return is negative. To control residuals did not need more than two lags of DCC-MGARCH. To test whether residuals aren't autocorrelated was used the Q test of Ljung Box, as shown the Table 3.

The next step of the study was to estimate the structural betas through a level local model with variance of the level fixed and time-varying betas. Estimates of residuals and diagnosis of the structural model can be found in Appendix I. The structural model estimates the betas smoothed, as shown in Figure 1 (see Appendix II). The betas estimated by two methods are tested to see if they have explanatory power on average excess returns in cross section. 
Table 3. Diagnostic Checking for DCC-MGARCH

\begin{tabular}{|c|c|c|c|c|c|c|c|c|}
\hline Asset & $Q_{1}(5)$ & $Q_{1}(10)$ & $Q_{1}(15)$ & $Q_{1}(20)$ & $Q_{2}(5)$ & $Q_{2}(10)$ & $Q_{2}(15)$ & $Q_{2}(20)$ \\
\hline ambv4 & 5.14 & 8.85 & 13.77 & 16.48 & 3.67 & 6.97 & 9.13 & 12.51 \\
\hline ibov & 14.17 & 21.68 & 30.49 & 41.46 & 9.66 & 24.55 & 31.65 & 39.39 \\
\hline bbdc4 & 5.70 & 12.26 & 18.37 & 31.92 & 7.00 & 14.87 & 17.43 & 20.39 \\
\hline ibov & 7.98 & 15.57 & 18.71 & 24.69 & 4.20 & 12.35 & 14.77 & 15.23 \\
\hline brkm5 & 2.39 & 10.05 & 19.73 & 21.69 & 6.68 & 11.03 & 19.32 & 26.44 \\
\hline ibov & 7.91 & 9.45 & 12.76 & 16.22 & 10.97 & 25.28 & 29.18 & 30.26 \\
\hline brto4 & 1.11 & 4.95 & 8.55 & 16.81 & 1.72 & 3.42 & 4.17 & 8.69 \\
\hline ibov & 18.95 & 28.64 & 37.19 & 42.77 & 9.80 & 19.93 & 26.05 & 30.11 \\
\hline bbas3 & 4.08 & 8.82 & 15.66 & 19.67 & 1.96 & 5.99 & 16.29 & 24.29 \\
\hline ibov & 12.36 & 20.35 & 26.18 & 32.27 & 6.61 & 22.94 & 25.76 & 30.94 \\
\hline cmig4 & 0.63 & 3.35 & 10.30 & 12.85 & 3.27 & 4.19 & 8.66 & 17.23 \\
\hline ibov & 8.04 & 14.10 & 24.66 & 30.27 & 15.20 & 24.68 & 27.44 & 28.19 \\
\hline cruz3 & 0.57 & 3.21 & 5.73 & 9.99 & 1.46 & 12.30 & 18.47 & 27.98 \\
\hline ibov & 9.63 & 16.90 & 22.99 & 31.89 & 19.91 & 36.50 & 38.89 & 42.32 \\
\hline csna3 & 14.01 & 23.57 & 28.68 & 33.07 & 5.65 & 12.24 & 25.95 & 29.59 \\
\hline ibov & 11.65 & 16.91 & 23.03 & 26.50 & 22.90 & 31.75 & 34.80 & 35.30 \\
\hline elet3 & 4.85 & 7.48 & 13.53 & 18.62 & 7.74 & 14.97 & 24.02 & 29.88 \\
\hline ibov & 13.38 & 20.35 & 38.64 & 30.33 & 8.53 & 21.30 & 34.85 & 30.53 \\
\hline elet6 & 6.53 & 9.83 & 12.58 & 16.61 & 8.85 & 10.07 & 13.44 & 14.36 \\
\hline ibov & 16.27 & 25.24 & 36.28 & 40.90 & 2.80 & 8.35 & 11.14 & 12,65 \\
\hline embr3 & 11.19 & 31.86 & 39.65 & 64.59 & 0.25 & 0.68 & 0.99 & 1.70 \\
\hline ibov & 9.49 & 16.46 & 23.81 & 31.39 & 15.99 & 31.40 & 34.70 & 40.02 \\
\hline fibr3 & 1.67 & 2.80 & 7.18 & 18.98 & 4.87 & 17.28 & 21.11 & 24.64 \\
\hline ibov & 13.68 & 22.49 & 26.79 & 33.57 & 5.25 & 14.18 & 18.56 & 21.67 \\
\hline ggbr4 & 7.26 & 8.49 & 10.98 & 16.94 & 9.54 & 11.68 & 13.15 & 20.89 \\
\hline ibov & 21.89 & 28.47 & 39.41 & 50.21 & 21.91 & 30.59 & 44.86 & 47.74 \\
\hline goau4 & 8.28 & 9.44 & 13.59 & 25.44 & 8.03 & 11.53 & 17.39 & 20.91 \\
\hline ibov & 14.07 & 24.69 & 27.34 & 28.94 & 15.45 & 25.61 & 36.52 & 38.72 \\
\hline itsa4 & 1.13 & 6.35 & 11.62 & 16.09 & 3.12 & 6.66 & 13.33 & 14.81 \\
\hline ibov & 13.28 & 22.73 & 32.87 & 37.12 & 6.40 & 23.73 & 28.88 & 30.20 \\
\hline itub4 & 2.13 & 4.55 & 8.24 & 25.35 & 6.90 & 20.02 & 24.86 & 29.90 \\
\hline ibov & 14.20 & 23.36 & 25.75 & 32.05 & 11.96 & 20.34 & 21.56 & 26.70 \\
\hline klbn4 & 4.54 & 6.37 & 11.29 & 15.30 & 10.17 & 12.73 & 14.68 & 15.79 \\
\hline ibov & 8.96 & 17.98 & 23.43 & 26.74 & 8.73 & 22.92 & 26.16 & 26.79 \\
\hline lame4 & 3.80 & 10.43 & 12.60 & 17.54 & 2.46 & 13.29 & 16.01 & 21.56 \\
\hline ibov & 12.42 & 17.84 & 24.79 & 26.34 & 21.58 & 33.43 & 41.03 & 43.87 \\
\hline ligt3 & 2.66 & 3.85 & 6.13 & 8.13 & 2.74 & 7.52 & 12.19 & 18.01 \\
\hline ibov & 8.25 & 13.98 & 18.94 & 23.01 & 9.88 & 25.00 & 26.96 & 30.78 \\
\hline Iren3 & 26.67 & 28.53 & 30.80 & 35.06 & 10.44 & 14.95 & 19.21 & 26.63 \\
\hline ibov & 2.78 & 7.95 & 11.00 & 14.42 & 1.35 & 5.81 & 7.15 & 10.82 \\
\hline pcar4 & 2.50 & 10.33 & 13.44 & 15.41 & 10.14 & 15.81 & 17.48 & 19.67 \\
\hline
\end{tabular}




\begin{tabular}{|l|l|l|l|l|l|l|l|l|}
\hline ibov & 1.74 & 7.95 & 8.49 & 18.68 & 2.82 & 8.68 & 9.96 & 15.14 \\
\hline petr3 & 2.08 & 6.28 & 10.38 & 13.18 & 5.41 & 10.40 & 12.91 & 14.64 \\
\hline ibov & 2.70 & 10.08 & 11.77 & 21.05 & 2.14 & 14.00 & 16.63 & 20.95 \\
\hline petr4 & 9.88 & 12.41 & 14.42 & 16.08 & 5.08 & 7.48 & 15.68 & 17.48 \\
\hline ibov & 2.20 & 9.45 & 13.59 & 20.96 & 3.10 & 11.87 & 17.76 & 23.77 \\
\hline usim3 & 26.85 & 33.92 & 36.82 & 39.51 & 1.78 & 3.73 & 4.84 & 9.78 \\
\hline ibov & 7.91 & 14.07 & 21.23 & 28.37 & 20.54 & 32.90 & 38.69 & 43.52 \\
\hline usim5 & 1.15 & 3.97 & 8.33 & 10.24 & 5.86 & 9.90 & 11.66 & 20.27 \\
\hline ibov & 10.29 & 22.09 & 29.49 & 34.75 & 18.88 & 27.77 & 32.05 & 33.70 \\
\hline vale3 & 7.56 & 10.41 & 15.43 & 16.61 & 7.66 & 19.68 & 22.09 & 23.95 \\
\hline ibov & 14.20 & 25.93 & 36.46 & 44.04 & 13.98 & 23.34 & 31.53 & 33.20 \\
\hline vale5 & 1.30 & 4.57 & 9.06 & 15.97 & 12.46 & 15.11 & 17.73 & 18.44 \\
\hline ibov & 12.76 & 22.96 & 37.74 & 42.33 & 5.71 & 22.36 & 33.30 & 35.22 \\
\hline vivt4 & 5.21 & 7.42 & 9.68 & 14.27 & 9.81 & 22.02 & 24.06 & 28.37 \\
\hline ibov & 9.69 & 14.89 & 17.48 & 19.58 & 6.91 & 12.90 & 16.91 & 23.47 \\
\hline
\end{tabular}

The betas estimated (see table 4), except ELET6, ELET3 and USIM5 are smaller than 1, characterizing that the stocks are considered defensive for investors. This result was expected and is in line with the results found by Paiva (2005), given that the shares that remain long in Ibovespa are considered safer by agents.

The structural beta follows the movements of the conditional betas. The conditional betas have more "nervous" behavior that the structural betas. Besides the structural and conditional betas, the conditional variances were estimated for each asset searched. The analysis of the conditional variance is important in the financial market, because it is from the same which is calculated VaR (Value at Risk), another widely used measure of risk. Then we calculated the conditional correlations between each asset and the Ibovespa, as shown Figure 3. The study of correlation time-varying allows the investor to know what stock is more impacted event of a change in market index and, thus, make their hedging strategies. There are times wherein the stocks of Renner (LREN3), Vale (VALE3) and Embraer (EMBR3) have a negative correlation with the Ibovespa, indicating a fall in the index increases the price of these stocks. The stock of Vivo (vivt4) has a decreasing correlation with the Ibovespa over time, from an average of 0.75 at the beginning of the series to 0.50 in recent times.

Table 4 shows the average betas estimated by the two models. Note that, on average the betas estimated by the two models have similar values, although their trajectories are often distinct.

Then it was verified whether the average conditional betas and average structural betas explain the cross section of excess returns. The results are shown in Table 5.

The survey found that the conditional beta has better explanatory power of returns than the betas estimated by the structural model. However, when tested without the intercept, the conditional beta wasn't significant, showing that the CAPM fails on many occasions and not always the asset at higher non-diversifiable risk offers the highest expected return. Therefore, the research concludes that, for the Brazilian stock market in the period surveyed there is no evidence that the action with greater nondiversifiable risk represented by beta offered higher return to investors.

The structural betas don't explain the cross section of returns, showing that the CAPM, tested using the methodology of Fama and McBeth (1973) doesn't fit well to the stock market in Brazil.

One of the research findings is that the constant beta serves only for reference if action follows or not the market's performance in a given period, but not enough to serve as a good measure of risk. As demonstrated, the beta isn't constant. The dynamic betas are a better approximation of market risk as they increase in times of crisis and increased risk aversion. 
Table 4. Average Dynamic Betas

\begin{tabular}{|c|c|c|}
\hline Asset & $\begin{array}{c}\text { Average Conditional } \\
\text { Betas }\end{array}$ & Average Structural Betas \\
\hline ambv4 & 0.49 & 0.50 \\
\hline bbdc4 & 0.85 & 0.85 \\
\hline brkm5 & 0.77 & 0.77 \\
\hline brto4 & 0.93 & 0.89 \\
\hline bbas3 & 0.82 & 0.43 \\
\hline cmig4 & 0.89 & 0.89 \\
\hline cruz3 & 0.52 & 0.52 \\
\hline csna3 & 0.89 & 0.89 \\
\hline elet3 & 1.05 & 1.03 \\
\hline elet6 & 1.08 & 1.04 \\
\hline embr3 & 0.48 & 0.50 \\
\hline fibr3 & 0.65 & 0.66 \\
\hline ggbr4 & 0.91 & 0.90 \\
\hline goau4 & 0.68 & 0.81 \\
\hline itsa4 & 0.79 & 0.80 \\
\hline itub4 & 0.82 & 0.82 \\
\hline klbn4 & 0.73 & 0.74 \\
\hline lame4 & 0.69 & 0.68 \\
\hline ligt3 & 0.81 & 0.79 \\
\hline lren3 & 0.95 & 0.94 \\
\hline pcar4 & 0.49 & 0.50 \\
\hline petr3 & 0.91 & 0.89 \\
\hline petr4 & 0.92 & 0.91 \\
\hline usim3 & 0.58 & 0.58 \\
\hline usim5 & 1.04 & 0.73 \\
\hline vale3 & 0.60 & 0.82 \\
\hline vale5 & 0.82 & \\
\hline vivt4 & 0.71 & 0.70 \\
\hline & & \\
\hline
\end{tabular}

Table 5. Estimation of the equation of cross section of excess returns with conditional betas

\begin{tabular}{|c|l|l|l|c|c|c|c|}
\multicolumn{8}{|c|}{$R_{a}=\kappa_{0}+\kappa_{1} \beta_{a}+\kappa_{2} \beta_{a}^{2}+\kappa_{3} S_{e a}+\eta_{a}$} \\
\hline Model & $\kappa_{0}$ & $\kappa_{1}$ & $\kappa_{2}$ & $\kappa_{3}$ & $Q_{1}(5)$ & $Q_{2}(5)$ & $\begin{array}{c}\text { JB Test } \\
\text { (p-value })\end{array}$ \\
\hline 1 & $-0.0066^{* *}$ & $0.0210^{*}$ & $-0.0135^{* *}$ & $-0.0003^{* * *}$ & 8.86 & 2.35 & 0.98 \\
\hline 2 & -0.0059 & 0.0163 & -0.01058 & & 1.43 & 2.67 & 0.15 \\
\hline 3 & $0.0014^{*}$ & $-0.0018^{*}$ & & & 8.43 & 5.84 & 0.43 \\
\hline 4 & & $0.0005^{* * *}$ & & & 11.96 & 1.31 & 0.30 \\
\hline
\end{tabular}

$*, * *$ and $* * *$ indicate no significance at levels of $1 \%, 5 \%$ and $10 \%$, respectively.

The main contribution of this research is the estimation of conditional betas. It is important the use of alternative risk measure that not only VaR, which is the most used on the market. The conditional beta, unlike VaR, uses the conditional variance and conditional covariance between the market and 
active. The disadvantage of the beta to the VaR is that the beta is not expressed in monetary value, but as a sensitivity coefficient of share in relation to the market.

Another contribution of estimation of dynamic betas for the Brazilian market is the use of different weights for different stocks in Long x Short. Assuming that betas vary, the investor can change each time the position of each asset in your portfolio, not just applying equal values in each of the assets.

Unlike Hueng and Huang (2008), this work did not find an asymmetric relation between risk and return, because the dynamic betas estimated have values close to the static betas estimated for Brazilian market by Godeiro (2012).

The results are in line with Flister et al. (2011), in that time-varying betas provide a better fit for the CAPM. The work Tambosi Filho et al. (2007) also points to the validity of the conditional CAPM.

Given the failure of beta in provide a reliable measure of risk; the research measured the relationship between the market conditional variances, estimated by DCC-MGARCH and excess return of assets. The goal is to estimate the "cost of risk", in other words is to check in as increase the risk when it increases the expected return.

The parameters of premium and cost of risk were estimated following the methodology developed by Harvey (1989). The author assesses the relationship between the innovations of the excess return and the variance or standard deviation of market. Also according to Harvey (1989) the parameters of risk premium represents the risk aversion of the agents. To retrieve the parameters were used the conditional variance and standard deviation conditional estimated by $\mathrm{MGARCH}$, as well as innovations in excess returns of assets and market. It is expected that an inverse relationship occurs between excess return and volatility, indicating that an increase in the volatility decreases excess return expected.

Fourteen of the twenty-eight Ibovespa stocks analyzed presented results in accordance with the results of Kumar et. al (2008), since these actions had an inverse relationship between return and volatility. This type of behavior is not typical of stocks classified as defensive by market agents.

The analysis of Table 6 provides the identification of some facts. Assets with the coefficients of relative risk aversion negatives are a good alternative in times of increased in volatility, because they have a direct relationship with the conditional variance. These actions, as shown in the table are shares of the electricity sector, as CMIG4 and shares that have a large weight in the index, as Petrobras and Vale. This is because in times of crisis and increased risk aversion there is a change in the preference basket of asset of investors. They tend to decrease positions in stocks Small Caps and increasing position in treasuries or shares considered safer by the market. The ordinary shares of Usiminas had the highest inverse relation with volatility, indicating that they are significantly impaired when there is increase in risk aversion. Therefore, one arrives at the conclusion that the conditional variance has a good explanatory power on the excess return of assets and the methodology developed by Harvey (1989) has a good performance in the Brazilian stock market, unlike the methodology of Fama and Mcbeth (1973) who did not achieve a satisfactory result. 
Table 6. Parameters of Relative Risk Aversion

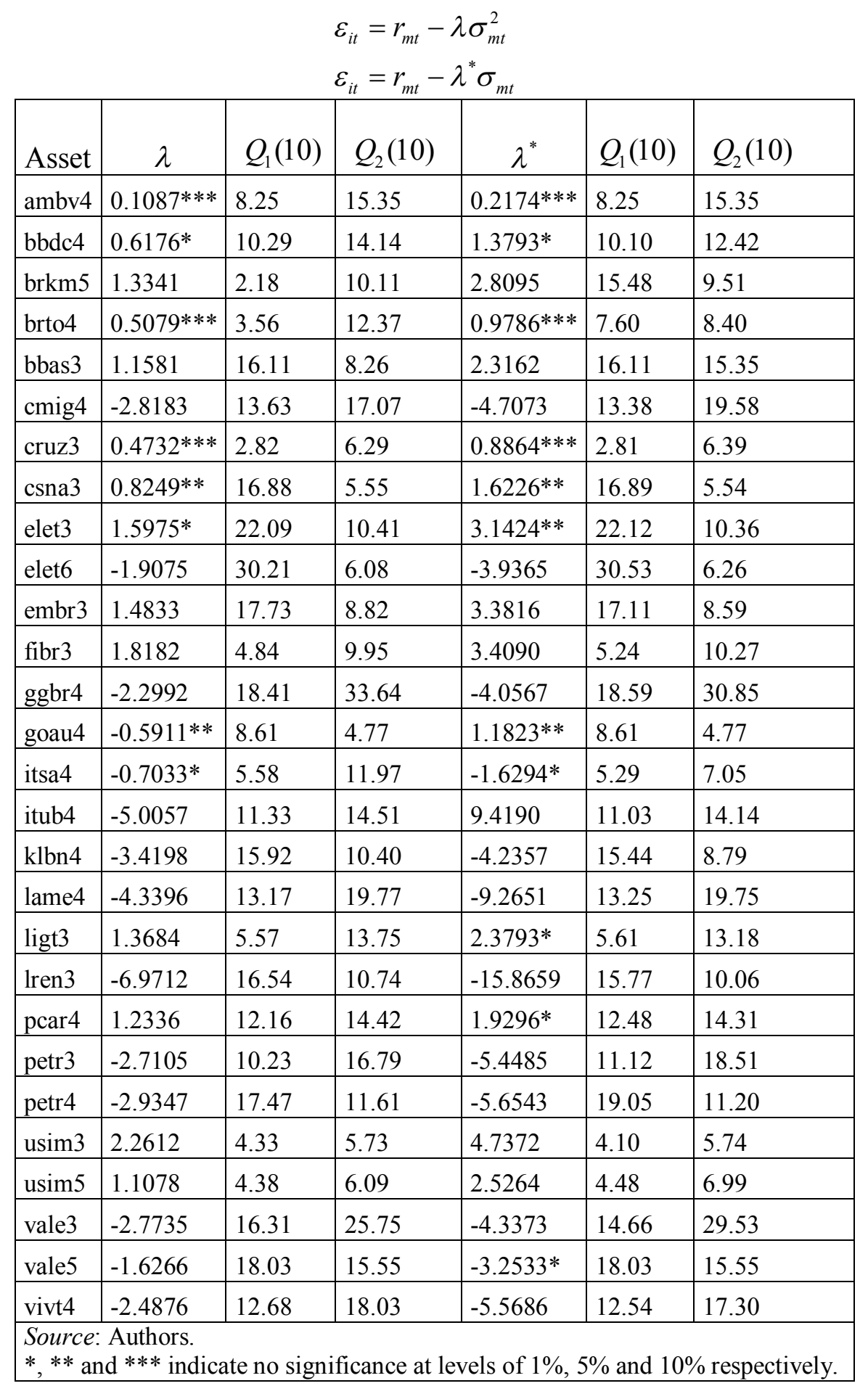

\section{Conclusions}

The research proposed a test of the capital asset pricing model for the Brazilian stock market using the MGARCH model developed by Tse and Tsui (2002). For comparison were also obtained estimates of betas smoothed in time. It was found that the estimated betas have a significant increase in times of crisis, indicating increase in non-diversifiable risk these periods. The increased risk occurs because of the loss of attractiveness of equities papers and hence the fall in their prices.

The volatility of twenty-eight asset surveyed was estimated from the DCC-MGARCH model, verifying that the crisis of 2008 is the period when risk aversion reaches its peak, because in this period occur the highest level of conditional variance. Stocks of companies like Bradesco, Petrobras and Vale had a lower volatility than other companies in the sub-prime crisis, which strengthens the 
argument that these companies are defensive because are most demanded in times of crisis. The parameters of relative risk aversion estimated also suggest the same conclusion.

The test methodology of Fama and Mcbeth (1973) isn't valid for Brazil in the period surveyed, since there was a no significant relationship between excess returns and betas, ie, stocks with higher non-diversifiable risk weren't the stocks with greatest excess return. The parameters that measure relative risk aversion according to Harvey (1989) were significant and are valid as a measure of risk for Brazil during the interval studied.

The estimate of conditional correlations shows relevant information. Despite the Vale (VALE5) preference stock have the highest unconditional correlation with the Ibovespa; analyzing the conditional correlation appears that there were periods in which the correlation between the variables mentioned was less than 0.20. Likewise, the share of Gerdau Metalúrgica (GOAU4) had the lowest unconditional correlation with the market index, when dynamic analysis is done there are times when the conditional correlation comes close to one, indicating that the share follows the movements of market in these intervals.

It is important when working with financial data, the modeling of stylized facts. This research attempted to do this by not only estimating a model for the conditional mean, but also for the conditional variances. The stylized fact of fat tails was modeled using t-distribution. Regarding the asymmetry was used GJR model, aiming to replicate the fact that the risk averse agent gives greater weight to negative than positive results in its utility function.

For future research we suggest that betas are estimated by various methods offered by MGARCH models, such as CCC, BEKK and DCC of Engle himself with checking if they have the power to explain the cross section of excess returns, and also can be analyzed assets contained in other indexes besides the Ibovespa.

\section{References}

Alencastro, D. (2009) Empirical analysis of the basic CAPM to Brazil after the implementation of the Real Plan. Dissertation, 74p. Porto Alegre: PUCRS.

Andrews, D. W. K (1993). Tests for parameter instability and structural change with unknown change point. Econometrica, 61, 821-856.

Bollerslev, T.; Engle, R.F.; Wooldridge, J. (1988) A capital asset pricing model with time varying covariances. Journal of Political Economy, 96, 116-131.

Campbell, J.Y. (1987) Stock returns and term structure. Journal of Financial Economics, 18, 373-400.

Campbell, J.Y., Lo, A.W., Mackinlay, A.C. (1997) The Econometrics of Financial Markets. Princeton, NJ: Princeton University Press, 651p.

Danielsson, J. (2011) Financial Risk Forecasting. New York: Wiley Finance, 325 p.

Davidian, M.; Carrol, R.J. (1987) Variance function estimation. Journal of the American Statistical Association, 82,179-1091.

Engle, R.F.; Kroner, K.F. (1995) Multivariate Simultaneous Generalized ARCH. Econometric Theory, $11,122-150$.

Fama, E.F.; Macbeth, J.D. (1973) Risk, return and equilibrium: empirical tests. Journal of Political Economy, 81, 607-636.

Flister, F.V.; Bressan, A.A.; Amaral, H.F. (2011) Conditional CAPM in the Brazilian Market: A Study of the Effects Momentum, Size and Book-to-Market between 1995 and 2008. Brazilian Review of Finance, 9, 105-129.

Ghysels, E. (1998) On stable factor structures in the pricing of risk: do time varying betas help or hurt. Journal of Finance, 53, 549-574.

Glosten, L.R.; Jaganathan, R.; Runkle, D. (1993) On the relation between the expected value and the volatility of the normal excess return on stocks. Journal of Finance, 48 1779-1801.

Godeiro, L.L. (2012) An empirical application of the CAPM to the Brazilian capital market. Dissertation, 60p. São Paulo: PUCSP.

Hamilton, J.D. (1994) Time Series Analysis. Princeton, NJ: Princeton University Press, 783 p.

Harvey, C. (1989) Is expected compensation for market volatility constant through time? Working paper, Duke University. 
Harvey, C. (1989a) Time-Varying Conditional Covariances in Tests of Asset Pricing Models. Journal of Financial Economics, 24, 289-317.

Huang, P.; Hueng, C.J. (2008) Conditional Risk-Return Relationship in a Time-Varying Beta

Model. Quantitative Finance, 8, 381-390.

Kumar, P.; Sorescu, S.M.; Boehme, R.D.; Danielsen, B.R. (2008) Estimation Risk, Information, and the Conditional CAPM: Theory and Evidence. Review of Financial Studies, 21(3), 1037-1075.

Mamaysky, R.; Spiegel, M. E.; Zhang, H. (2008) Estimating the Dynamics of Mutual Fund alphas and Betas. Review of Financial Studies, 21(1), 233-264.

Markowitz, H. (1952) Portfolio Selection. Journal of Finance, 7, 77-91.

Merton, R.C. (1980) On estimating the expected return on the market: an exploratory investigation. Journal of Financial Economics, 8, 323-361.

Ng, L. (1991), Tests of the CAPM with Time-Varying Covariances: A Multivariate GARCH Approach. The Journal of Finance, v. 46, p.1507-1521.

Paiva, F.D. (2005), Asset Pricing Models of Financial Single Factor: An Empirical Test of the DCAPM and CAPM. Research and Administration Books, 12, 49-65.

Sharpe, W.F. (1964), Capital Asset Prices: A Theory of Market Equilibrium Under Conditions of Risk. Journal of Finance, 19, 425-442.

Tambosi Filho, E.; Garcia, F.G.; Bertucci, L. (2007) A, Empirically Testing the CAPM conditional of expected returns of portfolios of Brazilian, Argentine and American market. Journal of Management USP, 14(4), 63-75.

Tse, Y.K.; Tsui, A.K.C. (2002) A Multivariate Generalized Autoregressive Conditional Heteroscedasticity Model with Time-Varying Correlations. Journal of Business \& Economic Statistics, 20(3), 351-36.

Wang, K.Q. (2003), Asset Pricing with Conditioning Information: A New Test. Journal of Finance, $58,161-196$. 


\section{Appendix I}

Table I.1. Descriptive statistics of daily data of excess return of assets, the excess return of the market and the Selic rate

\begin{tabular}{|c|c|c|c|c|c|c|c|c|c|c|c|}
\hline Asset & Mean & Standard & Min & Max & Skewness & Kurtosis & $\mathrm{AC}$ (One lag) & AC (One lag) & $\mathrm{JB}$ & LB & LB squared of returns \\
\hline & & Deviation & & & & & returns & of squared returns & (p-value) & 20 lags (p-value) & 20 lags (p-value) \\
\hline selic & $0.0694 \%$ & $0.03 \%$ & $0.03 \%$ & $0.21 \%$ & 1.80 & 6.57 & 0.99 & 0.99 & 0.00 & 0.00 & 0.00 \\
\hline ibov & $-0.0083 \%$ & $2.22 \%$ & $-17.34 \%$ & $28.71 \%$ & 0.45 & 17.05 & 0.03 & 0.21 & 0.00 & 0.00 & 0.00 \\
\hline ambv4 & $0.0419 \%$ & $2.18 \%$ & $-17.81 \%$ & $16.02 \%$ & -0.16 & 10.67 & 0.08 & 0.22 & 0.00 & 0.00 & 0.00 \\
\hline bbdc4 & $0.0173 \%$ & $2.52 \%$ & $-21.79 \%$ & $28.58 \%$ & 0.27 & 11.95 & 0.08 & 0.26 & 0.00 & 0.00 & 0.00 \\
\hline brkm5 & $-0.0343 \%$ & $2.75 \%$ & $-15.47 \%$ & $19.21 \%$ & 0.13 & 6.32 & 0.10 & 0.18 & 0.00 & 0.00 & 0.00 \\
\hline brto4 & $-0.0283 \%$ & $2.93 \%$ & $-18.06 \%$ & $20.90 \%$ & 0.06 & 7.41 & 0.05 & 0.18 & 0.00 & 0.00 & 0.00 \\
\hline bbas 3 & $-0.0105 \%$ & $2.83 \%$ & $-16.73 \%$ & $18.77 \%$ & 0.15 & 6.49 & 0.00 & 0.20 & 0.00 & 0.01 & 0.00 \\
\hline cmig4 & $0.0062 \%$ & $2.78 \%$ & $-27.91 \%$ & $26.29 \%$ & 0.26 & 12.20 & 0.08 & 0.21 & 0.00 & 0.00 & 0.00 \\
\hline cruz3 & $0.0438 \%$ & $2.29 \%$ & $-17.12 \%$ & $16,30 \%$ & 0.07 & 6.74 & -0.01 & 0.18 & 0.00 & 0.00 & 0.00 \\
\hline csna3 & $0.0363 \%$ & $2.82 \%$ & $-18.82 \%$ & $19.58 \%$ & 0.09 & 7.35 & 0.07 & 0.22 & 0.00 & 0.00 & 0.00 \\
\hline elet3 & $-0.0473 \%$ & $3.15 \%$ & $-17.92 \%$ & $28.30 \%$ & 0.48 & 9.79 & 0.10 & 0.26 & 0.00 & 0.00 & 0.00 \\
\hline elet6 & $-0.0319 \%$ & $3.12 \%$ & $-19.14 \%$ & $32.44 \%$ & 0.64 & 11.81 & 0.06 & 0.26 & 0.00 & 0.00 & 0.00 \\
\hline embr3 & $-0.0370 \%$ & $2.92 \%$ & $-38.46 \%$ & $29.95 \%$ & 0.48 & 24.09 & 0.15 & 0.20 & 0.00 & 0.00 & 0.00 \\
\hline fibr3 & $-0.0456 \%$ & $2.73 \%$ & $-19.10 \%$ & $17.59 \%$ & 0.35 & 7.67 & 0.09 & 0.23 & 0.00 & 0.00 & 0.00 \\
\hline ggbr4 & $0.0277 \%$ & $2.84 \%$ & $-16.19 \%$ & $20.83 \%$ & 0.20 & 6.91 & 0.11 & 0.22 & 0.00 & 0.00 & 0.00 \\
\hline goau4 & $0.0322 \%$ & $2.68 \%$ & $-27.63 \%$ & $21.62 \%$ & -0.03 & 9.86 & 0.07 & 0.24 & 0.00 & 0.00 & 0.00 \\
\hline itsa4 & $0.0284 \%$ & $2.43 \%$ & $-21.37 \%$ & $22.38 \%$ & 0.25 & 9.56 & 0.05 & 0.22 & 0.00 & 0.00 & 0.00 \\
\hline itub4 & $0.0284 \%$ & $2.47 \%$ & $-15.79 \%$ & $20.95 \%$ & 0.32 & 7.65 & 0.11 & 0.19 & 0.00 & 0.00 & 0.00 \\
\hline klbn4 & $-0.0086 \%$ & $2.97 \%$ & $-15.31 \%$ & $19.93 \%$ & 0.48 & 7.26 & -0.05 & 0.19 & 0.00 & 0.03 & 0.00 \\
\hline lame4 & $0.0201 \%$ & $3.01 \%$ & $-17.45 \%$ & $24.67 \%$ & 0.48 & 8.34 & 0.04 & 0.18 & 0.00 & 0.00 & 0.00 \\
\hline ligt3 & $-0.0822 \%$ & $3.15 \%$ & $-26.35 \%$ & $24.02 \%$ & 0.19 & 9.86 & 0.06 & 0.21 & 0.00 & 0.00 & 0.00 \\
\hline lren3 & $0.0396 \%$ & $2.13 \%$ & $-26.90 \%$ & $40.39 \%$ & 1.89 & 52.64 & 0.08 & 0.37 & 0.00 & 0.00 & 0.00 \\
\hline pcar4 & $-0.0023 \%$ & $2.47 \%$ & $-24.62 \%$ & $30.90 \%$ & 0.41 & 20.32 & 0.05 & 0.25 & 0.00 & 0.00 & 0.00 \\
\hline
\end{tabular}




\begin{tabular}{|c|c|c|c|c|c|c|c|c|c|c|c|}
\hline petr3 & $0.0210 \%$ & $2.78 \%$ & $-22.43 \%$ & $20.37 \%$ & -0.11 & 9.78 & 0.08 & 0.24 & 0.00 & 0.00 & 0.00 \\
\hline petr 4 & $0.0114 \%$ & $2.64 \%$ & $-21.26 \%$ & $20.95 \%$ & -0.11 & 10.84 & 0.09 & 0.33 & 0.00 & 0.00 & 0.00 \\
\hline usim3 & $-0.0050 \%$ & $2.81 \%$ & $-19.31 \%$ & $37.39 \%$ & 1.13 & 19.66 & 0.11 & 0.18 & 0.00 & 0.00 & 0.00 \\
\hline usim5 & $-0.0084 \%$ & $3.06 \%$ & $-18.28 \%$ & $16.58 \%$ & 0.03 & 6.06 & 0.10 & 0.20 & 0.00 & 0.00 & 0.00 \\
\hline vale3 & $0.0083 \%$ & $2.56 \%$ & $-20.60 \%$ & $29.75 \%$ & 0.30 & 12.82 & 0.03 & 0.08 & 0.00 & 0.00 & 0.00 \\
\hline vale5 & $0.0195 \%$ & $2.56 \%$ & $-16.49 \%$ & $38.40 \%$ & 0.83 & 18.24 & 0.03 & 0.10 & 0.00 & 0.00 & 0.00 \\
\hline vivt4 & $-0.0033 \%$ & $2.63 \%$ & $-20.68 \%$ & $40.77 \%$ & 0.90 & 25.03 & 0.03 & 0.25 & 0.00 & 0.00 & 0.00 \\
\hline
\end{tabular}

Table I.2. Estimation of equation of excess returns in cross section with structural betas.

\begin{tabular}{|c|c|c|c|c|c|c|c|}
\multicolumn{8}{c|}{$R_{a}=\kappa_{0}+\kappa_{1} \beta_{a}+\kappa_{2} \beta_{a}^{2}+\kappa_{3} S_{e a}+\eta_{a}$} \\
\hline Model & $\kappa_{0}$ & $\kappa_{1}$ & $\kappa_{2}$ & $\kappa_{3}$ & $Q_{1}(5)$ & $Q_{2}(5)$ & $\begin{array}{c}\text { JB test } \\
(\mathrm{p} \text {-value })\end{array}$ \\
\hline 1 & $-0.0736^{* * *}$ & $0.2951^{* * *}$ & $-0.2034^{* * *}$ & $-0.0094^{* * *}$ & 8.93 & 1.56 & 0.21 \\
\hline 2 & $-0.0690^{* * *}$ & $0.2115^{* * *}$ & $-0.1488^{* * *}$ & & 11.41 & 1.47 & 0.20 \\
\hline 3 & $0.0079^{* * *}$ & $-0.0086^{* * *}$ & & & 12.14 & 1.35 & 0.30 \\
\hline 4 & & $0.0012^{* * *}$ & & & 11.93 & 1.26 & 0.30 \\
\hline
\end{tabular}

Source: Authors.

$*, * *$ and $* * *$ indicate no significance at levels of $1 \%, 5 \%$ and $10 \%$.

\section{Table I.3. Estimation of variances according to the structural model.}

\begin{tabular}{|c|c|c|c|}
\hline Asset & Level & Irregular & Beta \\
\hline ambv4 & 0.00 & 0.00 & 0.0004 \\
\hline bbdc4 & 0.00 & 0.00 & 0.0019 \\
\hline brkm5 & 0.00 & 0.00 & 0.0010 \\
\hline brto4 & 0.00 & 0.00 & 0.0021 \\
\hline bbas3 & 0.00 & 0.00 & 0.0027 \\
\hline cmig4 & 0.00 & 0.00 & 0.0002 \\
\hline cruz3 & 0.00 & 0.00 & 0.0009 \\
\hline
\end{tabular}


Testing the CAPM for the Brazilian Stock Market Using Multivariate GARCH Between 1995 and 2012

\begin{tabular}{|c|c|c|c|}
\hline csna3 & 0.00 & 0.00 & 0.0008 \\
\hline elet3 & 0.00 & 0.00 & 0.0002 \\
\hline elet6 & 0.00 & 0.00 & 0.0001 \\
\hline embr3 & 0.00 & 0.00 & 0.0010 \\
\hline fibr3 & 0.00 & 0.00 & 0.0003 \\
\hline ggbr4 & 0.00 & 0.00 & 0.0002 \\
\hline goau4 & 0.00 & 0.00 & 0.0002 \\
\hline itsa4 & 0.00 & 0.00 & 0.0007 \\
\hline itub4 & 0.00 & 0.00 & 0.0003 \\
\hline klbn4 & 0.00 & 0.00 & 0.0007 \\
\hline lame4 & 0.00 & 0.00 & 0.0002 \\
\hline ligt3 & 0.00 & 0.00 & 0.0015 \\
\hline 1ren3 & 0.00 & 0.00 & 0.0020 \\
\hline pcar4 & 0.00 & 0.00 & 0.0028 \\
\hline petr3 & 0.00 & 0.00 & 0.0011 \\
\hline petr4 & 0.00 & 0.00 & 0.0003 \\
\hline usim3 & 0.00 & 0.00 & 0.0007 \\
\hline usim5 & 0.00 & 0.00 & 0.0005 \\
\hline vale3 & 0.00 & 0.00 & 0.0018 \\
\hline vale5 & 0.00 & 0.00 & 0.0005 \\
\hline vivt4 & 0.00 & 0.00 & 0.0014 \\
\hline
\end{tabular}


Tabela I.4. Diagnostic Checking for Structural Model.

\begin{tabular}{|l|r|r|r|r|}
\hline Asset & $Q_{1}(5)$ & \multicolumn{1}{l}{$Q_{1}(10)$} & $Q_{1}(15)$ & $Q_{1}(20)$ \\
\hline ambv4 & 0.28 & 1.21 & 7.15 & 19.88 \\
\hline bbdc4 & 3.03 & 9.64 & 13.56 & 24.12 \\
\hline brkm5 & 1.91 & 14.38 & 19.99 & 26.53 \\
\hline brto4 & 4.69 & 5.81 & 8.86 & 10.51 \\
\hline bbas3 & 7.54 & 40.41 & 57.63 & 62.86 \\
\hline cmig4 & 1.61 & 3.00 & 6.69 & 9.89 \\
\hline cruz3 & 1.04 & 1.20 & 2.76 & 7.20 \\
\hline csna3 & 10.92 & 14.68 & 23.70 & 27.97 \\
\hline elet3 & 0.26 & 2.09 & 6.72 & 10.04 \\
\hline elet6 & 1.39 & 6.69 & 9.65 & 11.20 \\
\hline embr3 & 0.67 & 6.53 & 12.17 & 30.20 \\
\hline fibr3 & 1.72 & 3.73 & 5.94 & 10.65 \\
\hline ggbr4 & 4.48 & 5.03 & 7.96 & 14.54 \\
\hline goau4 & 3.19 & 9.73 & 10.15 & 10.82 \\
\hline itsa4 & 3.55 & 5.56 & 9.30 & 10.97 \\
\hline itub4 & 1.57 & 4.63 & 9.41 & 21.48 \\
\hline klbn4 & 0.91 & 1.62 & 5.50 & 13.16 \\
\hline lame4 & 23.65 & 27.32 & 29.55 & 53.09 \\
\hline ligt3 & 0.89 & 2.86 & 5.42 & 7.99 \\
\hline lren3 & 20.65 & 21.41 & 25.01 & 28.04 \\
\hline pcar4 & 8.94 & 16.21 & 26.32 & 29.27 \\
\hline petr3 & 3.50 & 16.98 & 22.29 & 32.37 \\
\hline petr4 & 6.58 & 12.67 & 17.62 & 20.46 \\
\hline usim3 & 2.12 & 3.09 & 5.90 & 14.57 \\
\hline usim5 & 1.36 & 3.81 & 8.53 & 13.82 \\
\hline vale3 & 3.01 & 4.86 & 11.79 & 15.31 \\
\hline vale5 & 2.71 & 3.51 & 7.95 & 14.83 \\
\hline vivt4 & 6.55 & 8.13 & 9.42 & 17.36 \\
\hline Source: & & & & \\
\hline
\end{tabular}




\section{Appendix II}

Figure 1. Dynamic Betas.

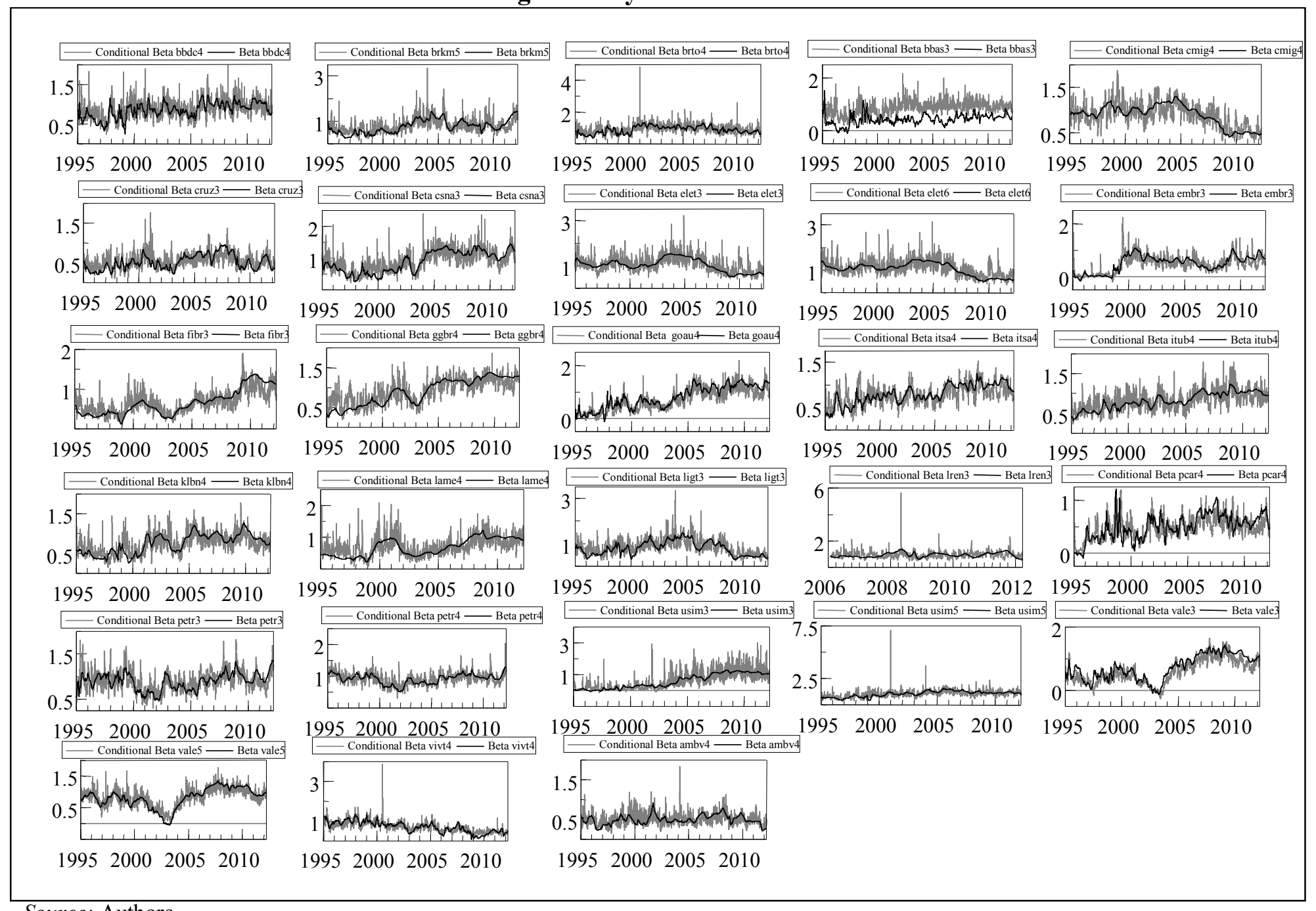

Source: Authors 


\section{Figure 2. Volatility of assets.}

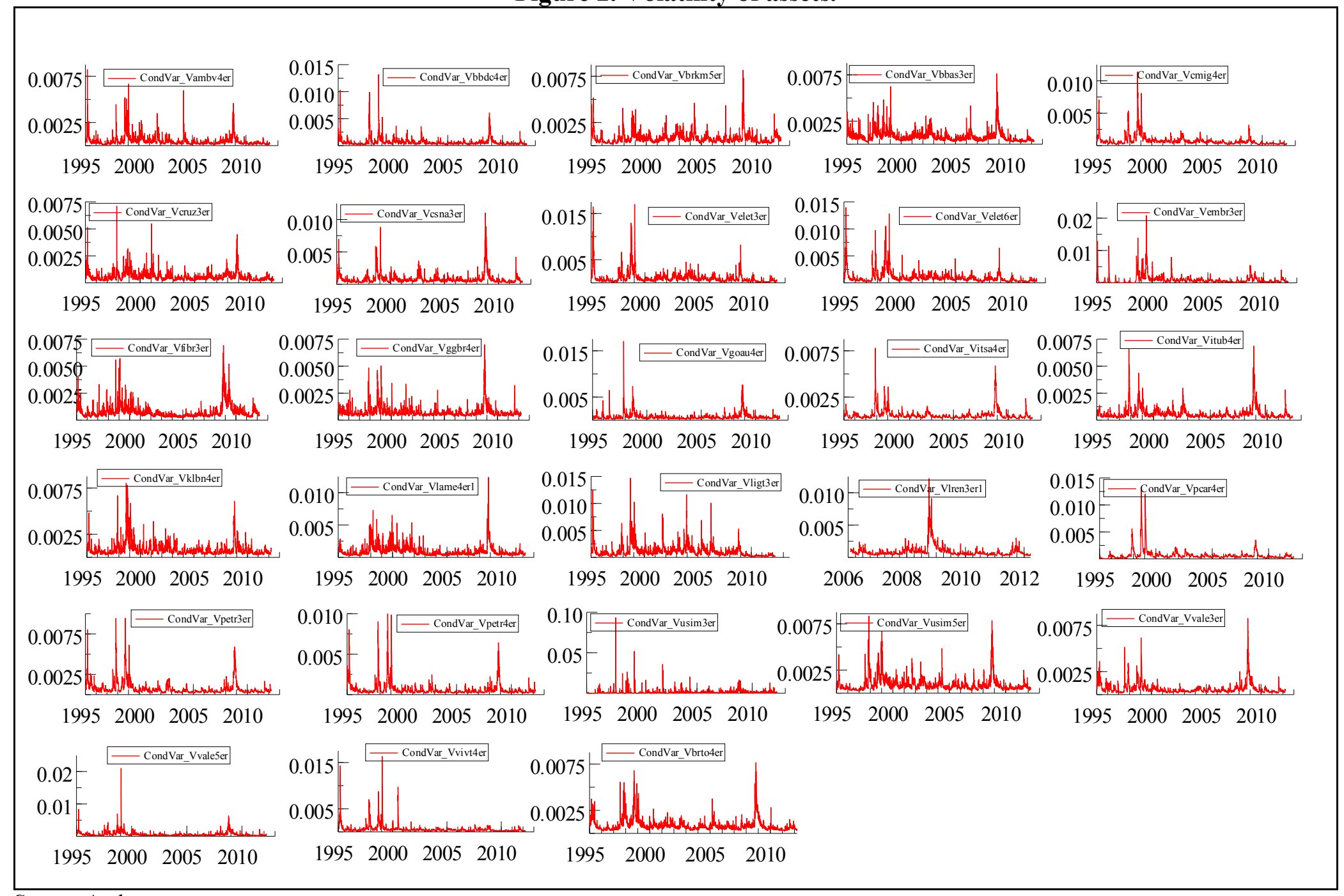

Source: Authors 
Figure 3. Conditional Correlation between assets and Ibovespa.

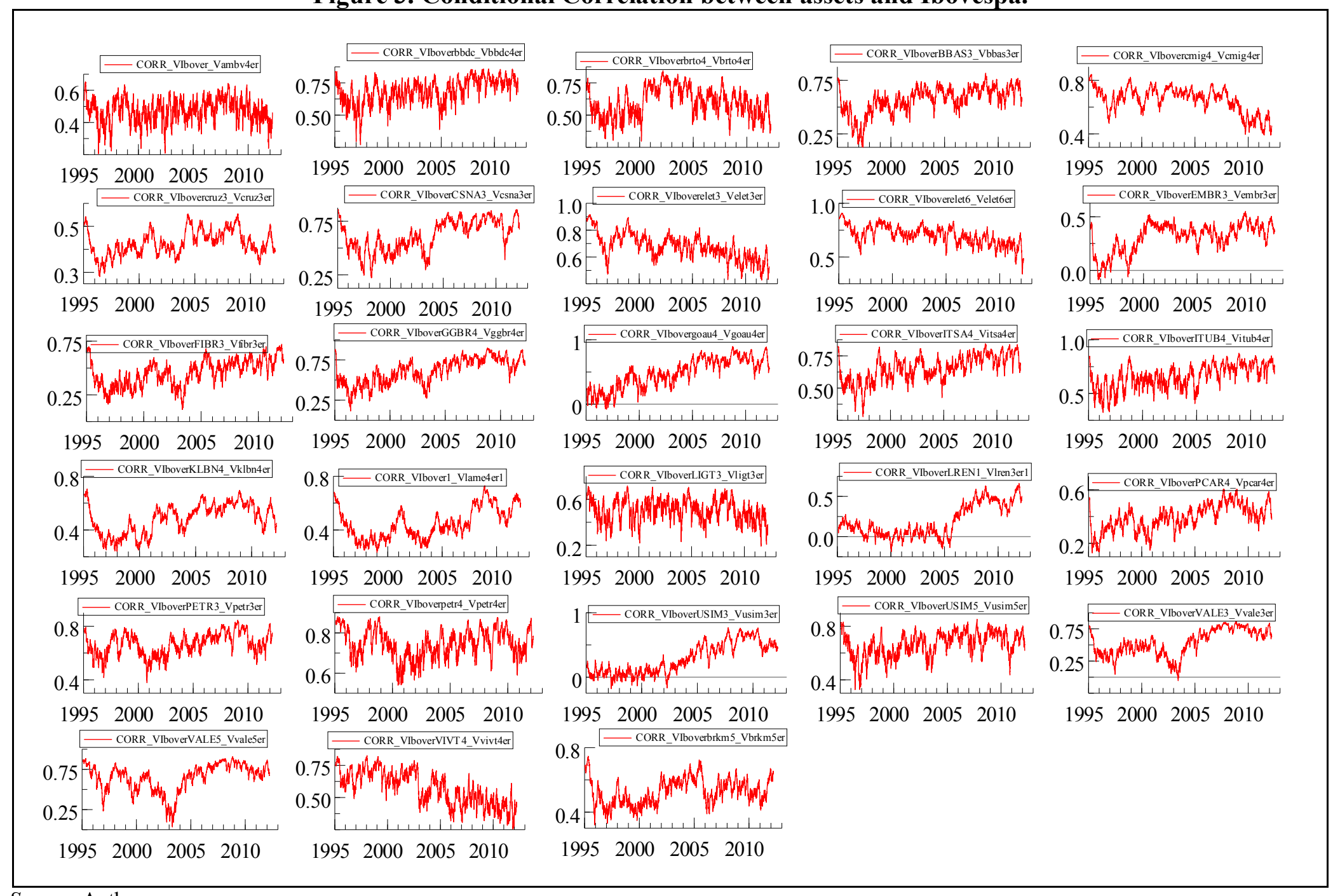

Source: Authors 